\title{
Modification of Shannon-Wiener Diversity Index towards Quantitative Estimation of Environmental Wellness and Biodiversity Levels under a Non-comparative Scenario
}

\author{
Dennis Omayio $^{1 *}$ Emmanuel Mzungu $^{2}$ \\ 1. School of Natural Sciences, Masinde Muliro University of Science and Technology, PO box 190-50100, \\ Kakamega, Kenya \\ 2. School of Natural Sciences, Masinde Muliro University of Science and Technology, PO box 190-50100, \\ Kakamega, Kenya
}

\begin{abstract}
Shannon-Wiener diversity index has been used extensively in environmental studies to estimate the species richness and abundance of ecosystems. The use of the index works very well under comparative situations; where one is comparing two or more environments simultaneously. However, in non-comparative situations the index interpretation becomes very limited in terms of the information it gives on the levels of an environment's species richness and abundance. Moreover, the magnitude of the Shannon diversity index denoted as $\left(H^{\prime}\right)$ is usually affected not only by the distribution of the data but also by the number of categories of species in an ecosystem. Thus, the recent increase of interest in quantifying diversity in different communities has increased the desire to develop comprehensive and highly discriminative approaches of analysis. Therefore, to add value to the index and eliminate selected weaknesses; the study sought to determine the effect of logarithmic indexing and variable integration on Shannon-Wiener diversity index model in discriminating all ecosystems involved in evaluation. Then determine quantitatively the environmental wellness and biodiversity levels of selected ecosystems. Therefore, the study utilized an eight step algorithm which was referred to as the 'Omatec Algorithm for Environmental Wellness Evaluation' that introduced new variables like; individual species number logarithmic index (ISNLI), mean individual species number logarithmic index (mISNLI) and integrated logarithmic index of an ecosystem (IIE). Using simulated cases of environments to test the algorithms outputs of their wellness; a negative control environment (biodiversity poor) with one species had an environmental wellness and biodiversity levels of $0 \%$. A positive control environment (biodiversity rich) with millions of species had an environmental wellness and biodiversity levels of $76.89 \%$. Two ecosystems with equal diversity index of 1.6094 and evenness of 1 with 5 categories of species each had a distinguishable environmental wellness and biodiversity levels of $25.22 \%$ and $16.92 \%$ respectively. Another, two ecosystems with the same diversity index of 0.5875 and evenness value of 0.4238 had distinguishable environmental wellness and biodiversity levels of $12.30 \%$ and $8.77 \%$ respectively. In conclusion the modification of Shannon-Wiener diversity index model discriminated the biodiversity levels of environments with same number of species categories despite having same richness and evenness values. Further, the environmental wellness percentages enabled estimation of the environmental quality under non-comparative situations. The modification of the model seems promising towards contributing to quantitative evaluation of environments towards their management.
\end{abstract}

Keywords: Environmental wellness, Shannon-Wiener, Quantitative, Modification, Biodiversity

DOI: $10.7176 / \mathrm{JEES} / 9-9-06$

Publication date:September $30^{\text {th }} 2019$

\section{Introduction}

Ecosystems vary widely in distribution, abundance, dominance, species composition (evenness) and biodiversity levels (Barrantes and Sandoval, 2009). This is caused by interaction of various factors in those species communities that lead to the differences in richness (Keylock, 2005). As a result, development of comprehensive indices of diversity that give projections on the wellness of those ecosystems has been an important ongoing process (Carlo et al., 1998). There are many indices which have been proposed for ecosystem richness and evenness determination under comparative situations. However, the Shannon-Wiener diversity index has been the most preferred for a long time due to its ease of calculation and interpretation (Carlo et al., 1998; Barrantes and Sandoval, 2009). This index is based on communication theory and stems from a common question in communication, how to predict the next letter in a message (Spellerbergy and Fedor, 2003).

Despite, its popularity the model has fundamental weaknesses that may limit its efficacy and varied applications (Ito, 2007; Zar, 2010). This is observed on the limitations of the model in its current form, in enabling evaluation 
of an ecosystems solely unless under comparative situations with another one. This scenario makes it difficult for researchers to effectively evaluate an ecosystem exclusively; because you must have an environment you are comparing to in order to make a valid assessment (Zar, 2010; Okpiliya, 2012). This can be a challenge in metapopulations such as islands which have unique environmental conditions that support specific species. Moreover, such ecosystems have dynamic consequences of movement among sub-populations due to spatial variations (Hanski, 1998). Hence, such environments need to be measured and quantified independently due to their uniqueness and limited points of reference.

Secondly, in some scenarios of evaluation the model lacks discriminatory powers that can distinguish diversity and evenness levels of such unique environments that clearly differ in their biodiversity levels (Okpiliya, 2012). For instance, using two simulated environments on table 1 below; the diversity and evenness levels calculated for environment 1 and 2 will be same despite the observable differences on the number of species:

Table 1: Unique cases in which the Shannon-Wiener diversity index fails to discriminate when calculating the diversity and evenness levels. This arises when the environments have equal number of species types/categories; in this case four species types for each environment as shown. Then each species category/type is exhibiting an equal number of individuals in its respective environment as illustrated; three and ten for environment 1 and environment 2 respectively.

\begin{tabular}{lc|lc}
\hline Environment 1 & Environment 2 \\
\hline Acacia sp & 3 & Warbugia sp & 10 \\
\hline Eucalyptus sp & 3 & Solanum sp & 10 \\
\hline Psidium sp & 3 & Datura sp & 10 \\
\hline Prunus sp & 3 & Mexican sp & 10 \\
\hline
\end{tabular}

This is a problem exhibited by a model that does not take into consideration all the possible sources of variation in a particular ecosystem (Zar, 2010). Further, the indices of richness determined by the model are qualitative and somehow vague. They don't estimate the levels of biodiversity in quantitative terms to enable determination of the restoration effort levels needed to improve its wellness and guide generally in decision making especially on cost of restoration or remediation (Peet, 1975; Jastrzebska et al., 2009). This is a consequence of its application as a ratio to the maximum diversity levels, where it does not take into account the fact that maximum diversity is limited by the number of species (Peet, 1975). In quantification of plants the index is unable to capture multidimensional characteristics hence difficult to know the relation between vegetative diversity and habitat quality/wellness levels (Jastrzebska et al., 2009). Also, the index is linked to the physical environment making it difficult to determine the health of an ecosystem; it correlates species richness and evenness with an assumption that they have a positive relationship. However, these two aspects may relate inversely and thus lead to unreliable results (Yeom and Hong Kim, 2011; MacDonald et al., 2016). In addition, the index lacks a probabilistic basis. Thus it's difficult to predict the distribution of the index, especially if the number and abundance is not known (Ricotta, 2006, Chao and Shen, 2012).

Amendments and supplementation of this index will increase its efficiency and sensitivity in measuring diversity (Milbrink, 1983). This is coupled with making the index a very important tool in monitoring biodiversity of biological systems. Aimed at driving the concerted efforts of quantification and conservation in the changing ecosystems, due to rise in anthropogenic activities which threatens the biosphere (Battisti, 2017). Therefore, this study sought to address some selected weaknesses, to enable assessment of an ecosystem solely under noncomparative situations, estimate its wellness levels and the levels of restoration needed through modification of the Shannon-Wiener Index. The objectives guiding the study were; to determine the effect of logarithmic indexing and variable integration on Shannon-Wiener diversity index model in discriminating unique ecosystems. Finally, to determine quantitatively the environmental wellness/biodiversity levels and restoration efforts levels needed of some selected ecosystems. 


\section{Materials and methods}

\subsection{Study approach}

The study strategy involved an eight steps algorithm which was labeled as Omatec algorithm for environmental wellness evaluation. The algorithm took advantage of logarithmic indexing which has been used extensively in evaluation of biological systems as per Hunt (1982), Parry (1990), Hunt et al. (2002) and Omayio et al. (2018). The eight steps of the algorithm were as follows:

\subsubsection{Step one; selection of ecosystems of study}

In this study environments $\mathrm{A}, \mathrm{B}, \mathrm{C}, \mathrm{D}, \mathrm{E}$ and $\mathrm{F}$ were simulated to specifically expose the weaknesses of the model in current form as will be shown in the results section. Environment (A) was simulated to be the negative control; that is an environment with the least species numbers (biodiversity poor). Whereas environment (F) was used as positive control (biodiversity rich) ecosystem. The other environments (B, C, D, \& E) were simulated to expose the weaknesses of the model in current form versus its outputs after the modification to demonstrate how the algorithm could solve the problem. Novel dimensions that introduced more variations into the model like; (ISNLI), (mISNLI) and integrated index were introduced to enhance its discriminatory power as demonstrated in the following steps.

\subsubsection{Step two; determination of Shannon diversity index and evenness}

This step involved the calculation of diversity indices and evenness of the simulated environments using the Shannon-Wiener diversity Index model as per Zar (2010) as illustrated below;

$$
H=-\sum P i L N P i
$$

Where; $(\mathrm{H})$ was the Shannon-Wiener diversity Index, Pi; was the relative proportion $(\mathrm{n} / \mathrm{N})$ of the individual of one particular species found. It entailed dividing (n) number of an individual species by the total number of all species individual numbers (N) found in a particular environment. Finally, (LNPi) was natural logarithm (LN) of the value Pi. Finally, the symbol implied $(\Sigma)$ summation of the outputs with the final value multiplied by negative one $(-1)$. In this step another variable the evenness of respective ecosystems was determined as per Zar (2010);

$$
\mathrm{E}=\frac{\mathrm{H}}{\mathrm{H}_{\mathrm{Max}}}
$$

Where; (E) was the determined evenness whereas $(\mathrm{H})$ was the Shannon-Wiener diversity Index and $\left(\mathrm{H}_{\mathrm{Max}}\right)$ was the natural logarithm of the number of specific categories/types of species in the sampled ecosystem (LN(n)).

\subsubsection{Step three; determination of individual species number logarithmic index (ISNLI)}

This was aimed at introducing a hidden source of variation that could be crucial in evaluating an ecosystem. This was determined by giving individual species numbers magnitude by use of natural logarithms so as to introduce a source of variation in Shannon-Wiener model in possible unique and general cases. The concept of logarithmic indexing has been emphasized by Parry (1990), Hunt et al. (2002) and Omayio et al. (2018) in evaluation of systems. For instance, if species X and $\mathrm{Y}$ had 40 and 10 individuals respectively in a certain specific ecosystem their ISNLI values would be $\mathrm{LN}(40)=3.6889$ and $\mathrm{LN}(10)=2.3026$ respectively (Omayio et al., 2018).

\subsubsection{Step four; determination of the mean individual species number logarithmic index (mISNLI)}

This was determined by use of a derived model that determined a simple average of all the individual species number logarithmic indices (ISNLI) determined in an ecosystem. This was based on the premises that the mean of individual species number logarithmic indices will represent well an ecosystem's power or efficiency of species colonization. Since, the logarithmic indices have been used effectively in generation of efficacy indices of biological systems under evaluation (Parry, 1990; Hunt et al., 2002 and Omayio et al., 2018) as illustrated:

$$
\operatorname{mISNLI}=\frac{\left(\mathrm{ISNLI}_{1}+\mathrm{ISNLI}_{2}+\mathrm{ISNLI}_{3}+\mathrm{ISNLI}_{4}+\cdots . . \mathrm{ISNLIn}\right)}{\mathrm{N}}
$$

Where; the (ISNL 1$),\left(\mathrm{ISNLI}_{2}\right),\left(\mathrm{ISNLI}_{3}\right)$ and $\left(\mathrm{ISNLI}_{4}\right)$ represents respective individual species number logarithmic indices of four different species in an example of an environment with four categories/types species identified. 
However, an ecosystem could have less or as many species as possible. Hence, the (ISNLI $\mathrm{n}_{\mathrm{n}}$ in the function to demonstrate the model's capability to accommodate as many species' ISNLI values as possible. The (N) in the model stood for the number of (ISNLI) values involved. This value varied depending on the different individual species in a particular ecosystem since it was basically the mean determination.

\subsubsection{Step five; determination of the integrated index of an ecosystem (IIE)}

This was determined by using a derived model that integrates all the indices involved through a simple average of the Shannon diversity index, Evenness and mISNLI. This based on the premise that mean index (Integrated index of ecosystem) will present the holistic performance of an environment's wellness visa vie individual indices as per Zar (2010) as demonstrated:

$$
\mathrm{IIE}=\frac{(\text { Shannon diversity index }+ \text { Evenness }+ \text { mISNLI })}{3}
$$

Where; (IIE) represents the integrated index of an ecosystem value which was a result of the average of the three variables (Shannon diversity index, Evenness and mISNLI). Hence, the division by the value three (3) above.

2.1.6 Step six; determination of the environmental wellness and biodiversity levels (EWBLP) under noncomparative scenarios

This step involved the determination of the environmental wellness and biodiversity levels using the integrated index from step five above. The model used was based on the maximum logarithmic index value 14.51, whose corresponding percentage was determined to be $100 \%$ by Omayio et al. (2018). Then, based on the rarely exceeded maximum likely Shannon-Wiener diversity index value of 4 and an evenness of 1 , an average value was determined (Magurran, 1988; Roth et al., 1994; Magurran, 2004; Zar, 2010). The three values (14.51, 4 and 1) derived an average of 6.503 that provided the maximum reference value in determining ecosystem wellness and biodiversity levels in percentage as illustrated in the model below. Therefore, with this knowledge the percentage of an environment's integrated index was determined based on the maximum reference value of 6.503 . The determined percentage was then taken as an estimator of the overall environmental wellness as illustrated:

$$
\mathrm{EWBLP}=\left(\frac{\text { Integrated Index of an ecosytem }}{6.503}\right) \times 100 \%
$$

Where; (EWBLP) represents the environmental wellness and biodiversity levels in percentage. The 6.503 is the maximum reference value of a very rich ecosystem as described above.

\subsubsection{Step seven; estimation of restoration effort levels needed on a particular environment}

This was determined by generating the difference that exists between $100 \%$ and the EWBLP value as illustrated below:

$$
\mathrm{REL}=(100 \%-\mathrm{EWBLP})
$$

Where; (REL) was the restoration effort levels needed on a particular environment and (EWBLP) represented the environmental wellness and biodiversity levels percentage as determined in step six.

\subsubsection{Step eight; interpretation of the calculated environmental wellness and biodiversity levels}

Finally, the calculated wellness levels were classified and identified as per the table 2 below which classified the quantitative scale of environmental wellness between $0 \%$ to $100 \%$. This was based on the modified four quarters proportions that divide the scale $0 \%$ to 100 of natural numbers as illustrated: 
Table 2: Identification Key of Environmental Wellness and Biodiversity levels

\begin{tabular}{l|c|c}
\hline $\begin{array}{c}\text { Percentage Intervals of Environmental } \\
\text { Wellness \& Diversity levels }\end{array}$ & $\begin{array}{c}\text { Colour Code } \\
\text { of respective intervals of } \\
\text { wellness \& Diversity }\end{array}$ & $\begin{array}{c}\text { Environmental } \\
\text { Wellness \& Diversity } \\
\text { levels }\end{array}$ \\
\hline From $0 \%$ to $24 \%$ & & $\begin{array}{c}\text { Low Environmental } \\
\text { Wellness/Biodiversity } \\
\text { levels }\end{array}$ \\
\hline From $25 \%$ to $49 \%$ & & $\begin{array}{c}\text { Moderate Environmental } \\
\text { Wellness/Biodiversity } \\
\text { levels }\end{array}$ \\
\hline From $50 \%$ to $100 \%$ & & $\begin{array}{c}\text { High Environmental } \\
\text { Wellness/Biodiversity } \\
\text { levels }\end{array}$ \\
\hline
\end{tabular}

\section{Results}

Based on evaluated environments the determined integrated index of an ecosystem (IIE) that represents an environmental wellness and biodiversity levels had its corresponding percentage increase proportionately with the richness of an ecosystem as demonstrated on tables $3,4,5,6,7$ and 8 .

In table 3, the environment (A) which was the simulated negative control had an integrated index of zero (0) calculated from the average of three parameters (Shannon diversity index, evenness and mISNLI) as demonstrated on table 3. The environmental wellness and biodiversity levels percentage (EWBLP) was zero percent $(0.00 \%)$. The restoration effort levels (REL) needed on the environment was estimated at $100 \%$. Based on the interpretation captured in table 2, this meant that the environment had low environmental wellness and biodiversity levels since its EWBLP value fell between the range of $0 \%$ to $24 \%$ with a brown color code (Table 2 ).

Table 3: showing Shannon-Wiener diversity index analysis of a negative control environment A with only one species and its subsequent modification through introduction of ISNLI, mISNLI, integrated index and determination of its levels of richness and wellness between a scale of $0 \%-100 \%$.

\begin{tabular}{|c|c|c|c|c|c|c|}
\hline Species & Number & $\mathbf{P i}$ & $\mathbf{L N}(\mathbf{P i})$ & \multicolumn{2}{|l|}{ PiLN(Pi) } & ISNLI \\
\hline Acacia sp & 1 & 1 & 0 & 0 & & $\mathrm{LN}(1)=0$ \\
\hline \multicolumn{4}{|c|}{ Total $(\mathrm{N})=1$} & $\sum=0$ & & \\
\hline \multicolumn{4}{|c|}{ The three parameters estimated $\rightarrow$} & Diversity index & Evenness & mISNLI \\
\hline & & & & 0 & 0 & 0 \\
\hline \multicolumn{7}{|c|}{$\begin{array}{l}\text { Average of the three parameters (Integrated Index })=0 \\
\text { Calculated percentage of environmental wellness and Biodiversity }=0.00 \% \\
\text { Restoration efforts levels estimation }=100 \%\end{array}$} \\
\hline
\end{tabular}


For the environment (B) demonstrated in table 4 the diversity index calculated by Shannon-Wiener diversity index model was 1.6094 with evenness of 1 . An integrated index of 1.10 was calculated from the average of three parameters (Shannon diversity index, evenness and mISNLI). The environmental wellness and biodiversity levels percentage (EWBLP) was $16.92 \%$. The restoration effort levels (REL) needed on the environment was estimated at $83.08 \%$. Thus, basing on the interpretation in table 2 , this meant that this simulated environment had low environmental wellness and biodiversity levels since its EWBLP value fell between the range of $0 \%$ to $24 \%$ with a brown color code (table 2).

Table 4: Showing Shannon-Wiener diversity index analysis of an environment B and its subsequent modification through introduction of ISNLI, mISNLI, integrated index and determination of its levels of richness and wellness between a scale of $0 \%-100 \%$.

\begin{tabular}{|c|c|c|c|c|c|c|}
\hline Species & Number & $\mathbf{P i}$ & $\mathbf{L N}(\mathbf{P i})$ & \multicolumn{2}{|l|}{$\operatorname{PiLN}(\mathrm{Pi})$} & ISNLI \\
\hline Eucalyptus sp & 2 & 0.2 & -1.6094 & -0.3219 & & $\mathrm{LN}(2)=0.6931$ \\
\hline Lantana $\mathrm{sp}$ & 2 & 0.2 & -1.6094 & -0.3219 & & $\mathrm{LN}(2)=0.6931$ \\
\hline Solanum sp & 2 & 0.2 & -1.6094 & -0.3219 & & $\mathrm{LN}(2)=0.6931$ \\
\hline Musa sp & 2 & 0.2 & -1.6094 & -0.3219 & & $\mathrm{LN}(2)=0.6931$ \\
\hline Psidium sp & 2 & 0.2 & -1.6094 & -0.3219 & & $\mathrm{LN}(2)=0.6931$ \\
\hline \multicolumn{4}{|c|}{ Total $(\mathrm{N})=10$} & $\sum=-1.6094$ & & \\
\hline \multicolumn{4}{|c|}{ The three parameters estimated $\rightarrow$} & Diversity index & Evenness & mISNLI \\
\hline & & & & 1.6094 & 1 & 0.6931 \\
\hline \multicolumn{7}{|c|}{$\begin{array}{l}\text { Average of the three parameters (Integrated Index) }=1.10 \\
\text { Calculated percentage of environmental wellness and Biodiversity }=16.92 \% \\
\text { Restoration efforts levels estimated }=83.08 \%\end{array}$} \\
\hline
\end{tabular}

For table 5, environment (C) despite having the same diversity index of 1.6094 and evenness of 1 as the ecosystem captured in table 4. Due to the modification an integrated index of 1.64 was calculated from the average of three parameters (Shannon diversity index, evenness and mISNLI). The environmental wellness and biodiversity levels percentage (EWBLP) was $25.22 \%$. The restoration effort levels (REL) needed on the environment was estimated at $74.78 \%$. Thus, basing on the interpretation in table 2 , this meant that this simulated environment had moderate environmental wellness and biodiversity levels since its EWBLP value fell between the range of $25 \%$ to $49 \%$ with a light green color code as illustrated in table 2 key of interpretation. 
Table 5: showing Shannon-Wiener diversity index analysis of an environment $C$ and its subsequent modification through introduction of ISNLI, mISNLI, integrated index and determination of its levels of richness and wellness between a scale of $0 \%-100 \%$.

\begin{tabular}{|c|c|c|c|c|c|c|}
\hline Species & Number & $\mathbf{P i}$ & $\mathbf{L N}(\mathbf{P i})$ & \multicolumn{2}{|l|}{$\operatorname{PiLN}(\mathbf{P i})$} & ISNLI \\
\hline Eucalyptus sp & 10 & 0.2 & -1.6094 & -0.3219 & & $\mathrm{LN}(10)=2.3026$ \\
\hline Lantana $\mathrm{sp}$ & 10 & 0.2 & -1.6094 & -0.3219 & & $\mathrm{LN}(10)=2.3026$ \\
\hline Solanum sp & 10 & 0.2 & -1.6094 & -0.3219 & & $\mathrm{LN}(10)=2.3026$ \\
\hline Musa sp & 10 & 0.2 & -1.6094 & -0.3219 & & $\mathrm{LN}(10)=2.3026$ \\
\hline Psidium sp & 10 & 0.2 & -1.6094 & -0.3219 & & $\mathrm{LN}(10)=2.3026$ \\
\hline \multicolumn{4}{|c|}{ Total $(\mathrm{N})=50$} & $\sum=-1.6094$ & & \\
\hline \multicolumn{4}{|c|}{ The three parameters estimated $\rightarrow$} & Diversity index & Evenness & mISNLI \\
\hline & & & & 1.6094 & 1 & 2.3026 \\
\hline \multicolumn{7}{|c|}{$\begin{array}{l}\text { Average of the three parameters (Integrated index) }=1.64 \\
\text { Calculated percentage of environmental wellness and Biodiversity }=25.22 \% \\
\text { Restoration efforts levels estimated }=74.78 \%\end{array}$} \\
\hline
\end{tabular}

For table 6 environment (D) with a diversity index of 0.5875 and evenness of 0.4238 , an integrated index of 0.80 was determined from the average of three parameters (Shannon diversity index, evenness and mISNLI). The environmental wellness and biodiversity levels percentage (EWBLP) was $12.30 \%$. The restoration effort levels (REL) needed on the environment was estimated at $87.70 \%$. Therefore, basing on the interpretation in table 2 , the ecosystem was classified to have low environmental wellness and biodiversity levels since its EWBLP value fell between the ranges of $0 \%$ to $24 \%$ with a brown color code as illustrated in table 2 key of interpretation. 
Table 6: showing Shannon-Wiener diversity index analysis of an environment D and its subsequent modification through introduction of ISNLI, mISNLI, integrated index and determination of its levels of richness and wellness between a scale of $0 \%-100 \%$.

\begin{tabular}{|c|c|c|c|c|c|c|}
\hline Species & Number & $\mathbf{P i}$ & $\mathbf{L N}(\mathbf{P i})$ & \multicolumn{2}{|l|}{$\operatorname{PiLN}(\mathbf{P i})$} & ISNLI \\
\hline Eucalyptus sp & 2 & 0.05 & -2.9957 & -0.1498 & & $\mathrm{LN}(2)=0.6931$ \\
\hline Lantana sp & 2 & 0.05 & -2.9957 & -0.1498 & & $\mathrm{LN}(2)=0.6931$ \\
\hline Solanum sp & 2 & 0.05 & -2.9957 & -0.1498 & & $\mathrm{LN}(2)=0.6931$ \\
\hline Musa sp & 34 & 0.85 & -0.1625 & -0.1381 & & $\mathrm{LN}(34)=3.5264$ \\
\hline \multicolumn{4}{|c|}{ Total $(N)=40$} & $\sum=-0.5875$ & & \\
\hline \multicolumn{4}{|c|}{ The three parameters estimated $\rightarrow$} & Diversity index & Evenness & mISNLI \\
\hline & & & & 0.5875 & 0.4238 & 1.4015 \\
\hline \multicolumn{7}{|c|}{$\begin{array}{l}\text { Average of the three parameters }(\text { Integrated index })=0.80 \\
\text { Calculated percentage of environmental wellness and Biodiversity }=12.30 \% \\
\text { Restoration efforts levels estimated }=87.70 \%\end{array}$} \\
\hline
\end{tabular}

In table 7 , the environment (E) had the same diversity index $(0.5875)$ and evenness $(0.4238)$ as the ecosystem in table 6. However, the modification generated an integrated index of 0.57 calculated from the average of three parameters (Shannon diversity index, evenness and mISNLI). The environmental wellness and biodiversity levels percentage (EWBLP) was $8.77 \%$. The restoration effort levels (REL) needed on the environment was estimated at $91.23 \%$. Thus, basing on the interpretation in table 2, this meant that this simulated environment had low environmental wellness and biodiversity levels since its EWBLP value fell between the range of $0 \%$ to $24 \%$ with a brown color code as illustrated in table 2 key of interpretation. 
Table 7: showing Shannon-Wiener diversity index analysis of an environment $E$ and its subsequent modification through introduction of ISNLI, mISNLI, integrated index and determination of its levels of richness and wellness between a scale of $0 \%-100 \%$.

\begin{tabular}{|c|c|c|c|c|c|c|}
\hline Species & Number & $\mathbf{P i}$ & $\mathbf{L N}(\mathbf{P i})$ & \multicolumn{2}{|l|}{$\operatorname{PiLN}(\mathrm{Pi})$} & ISNLI \\
\hline Eucalyptus sp & 1 & 0.05 & -2.9957 & -0.1498 & & $\mathrm{LN}(1)=0$ \\
\hline Lantana $\mathrm{sp}$ & 1 & 0.05 & -2.9957 & -0.1498 & & $\mathrm{LN}(1)=0$ \\
\hline Solanum sp & 1 & 0.05 & -2.9957 & -0.1498 & & $\mathrm{LN}(1)=0$ \\
\hline Musa sp & 17 & 0.85 & -0.1625 & -0.1381 & & $\mathrm{LN}(17)=2.8332$ \\
\hline \multicolumn{4}{|c|}{ Total $(\mathrm{N})=20$} & $\Sigma=-0.5875$ & & \\
\hline \multicolumn{4}{|c|}{ The three parameters estimated $\rightarrow$} & Diversity index & Evenness & mISNLI \\
\hline & & & & 0.5875 & 0.4238 & 0.7083 \\
\hline \multicolumn{7}{|c|}{$\begin{array}{l}\text { Average of the three parameters (Integrated index) }=0.57 \\
\text { Calculated percentage of environmental wellness and Biodiversity }=8.77 \% \\
\text { Restoration efforts levels estimated }=91.23 \%\end{array}$} \\
\hline
\end{tabular}

Finally, table 8 showing environment (F) which had huge numbers of individual species as a positive control (biodiversity rich ecosystem) was evaluated. The diversity index and evenness were 1.3153 and 0.7341 respectively. An integrated index of five (5) was determined from the average of three parameters (Shannon diversity index, evenness and mISNLI) as demonstrated on table 8 . The environmental wellness and biodiversity levels percentage (EWBLP) was $76.89 \%$. The restoration effort levels (REL) needed on the environment was estimated at $23.11 \%$. Based on the interpretation captured in table 2, this meant that the environment had high environmental wellness and biodiversity levels since its EWBLP value fell between the range of 50\% to $100 \%$ with a dark green color code as demonstrated in table 2 interpretation key.

\section{Discussion}

The value of any instrument, a tool or a predictive model in research and general use is based on its ability to efficiently and reliably determine an output in all situations presented to it (Hunt et al., 2002; Zar, 2010; Li, 2019). In this study the weaknesses of the Shannon-Wiener model were exposed in its inability to discriminate certain unique scenarios if they were to arise as demonstrated in table 4 and 5, where the environments evaluated had similar diversity indices despite having a varying individual species numbers. The same scenario is illustrated in table 6 and 7. This scenario is attributed to the general design of the Shannon-Wiener model where it relies on the variation that arises only from relative abundance and logarithmic magnitude of the same variable (Okpiliya, 2012) According to Zar (2010) for a model to effectively predict it should take into consideration all the possible sources of variation, which in this case was the limitation of the Shannon-Wiener diversity index model in its current form. 
Table 8: showing Shannon-Wiener diversity index analysis of an environment F (positive control; biodiversity rich environment) and its subsequent modification through introduction of ISNLI, mISNLI, integrated index and determination of its levels of richness and wellness between a scale of $0 \%-100 \%$.

\begin{tabular}{|c|c|c|c|c|c|c|}
\hline Species & Number & $\mathbf{P i}$ & $\mathbf{L N}(\mathbf{P i})$ & \multicolumn{2}{|l|}{$\operatorname{PiLN}(\mathbf{P i})$} & ISNLI \\
\hline Eucalyptus sp & $1,000,000$ & 0.238 & $\overline{-} 1.4355$ & -0.3416 & & $\mathrm{LN}(1000000)=13.82$ \\
\hline Lantana sp & 200,000 & 0.048 & 3.0366 & -0.1458 & & $\mathrm{LN}(200000)=12.21$ \\
\hline Solanum sp & 100,000 & 0.024 & $\begin{array}{l}- \\
3.7297\end{array}$ & -0.0895 & & $\mathrm{LN}(100000)=11.51$ \\
\hline Musa sp & 155,000 & 0.037 & 3.2968 & -0.1220 & & $\mathrm{LN}(155000)=11.95$ \\
\hline Pennisetum sp & $2,155,000$ & 0.514 & $-\overline{0.6655}$ & -0.3421 & & $\mathrm{LN}(2155000)=14.58$ \\
\hline Panicum sp & 584,000 & 0.139 & $\begin{array}{l}- \\
1.9733\end{array}$ & -0.2743 & & $\mathrm{LN}(584000)=13.28$ \\
\hline \multicolumn{4}{|c|}{ Total $(\mathrm{N})=4,194,000$} & $\sum=-1.3153$ & & \\
\hline \multicolumn{4}{|c|}{ The three parameters estimated $\rightarrow$} & Diversity index & Evenness & mISNLI \\
\hline & & & & 1.3153 & 0.7341 & 12.94 \\
\hline \multicolumn{7}{|c|}{$\begin{array}{l}\text { Average of the three parameters (Integrated index) }=5.00 \\
\text { Calculated percentage of environmental wellness and Biodiversity }=76.89 \% \\
\text { Restoration efforts levels estimated }=23.11 \%\end{array}$} \\
\hline
\end{tabular}

The limitation of the model generating qualitative indices that only make sense under comparative situations could be a bottleneck in making data based decisions when it comes to environmental management and conservation issues (Jastrzebska et al., 2009; Li, 2019). The transformation of the model towards generation of quantitative magnitudes ranging between $0 \%$ and $100 \%$ was made possible by introduction of some variation observed in individual species population through use of; the individual species number logarithmic index (ISNLI), mean individual species number logarithmic index (mISNLI) and the integrated index of an ecosystem (IIE). This enhanced the discriminatory power of the model; with similar logarithmic effect on parameters having been reported by Russell (1991), Hunt et al., (2002), Umbarger (2006) and Omayio et al. (2018). A similar concept has been used by Causton and Venus (1981), (Hunt, 1982) and (Parry,1990) in determination of efficacy levels of biological systems in fulfilling certain expected environmental occurrences like growth, disease management and epidemic development rates evaluation etc.

The quantitative evaluation of environmental wellness and biodiversity levels for a particular ecosystem independently under non-comparative situations was made possible because of the continuum nature of logarithmic values (Russell, 1991; Umbarger, 2006; Omayio, 2018). This continuous nature of the values has extensively been demonstrated by Omayio et al. (2018) in the development of a logarithmic table values with their corresponding percentages. The nature of the values allowed for a modified suitable scale to be generated that 
could estimate the integrated index's percentage value.

\section{Conclusion}

In conclusion the introduction of individual species number logarithmic indexing (ISNLI) that leads to the generation of a third variable which is called the mean individual species number logarithmic index (mISNLI), and integrated index enabled Shannon-Wiener Index to exhibit an ability to significantly distinguish levels of biodiversity in ecosystems' evaluation. This was on unique ecosystems that were indistinguishable before due to the limitations of the model. This is clearly demonstrated on tables 4 and 5 where the ecosystems have the same diversity index and evenness value despite having different number of species. Also, in tables 6 and 7 the same scenario is observed.

Also, the environmental wellness and biodiversity levels can be estimated in a quantitative scale of between $0 \%$ to $100 \%$. These ecosystems levels of wellness vary in magnitude as anticipated. The modification complements the Shannon-Wiener method of ecosystem analysis by giving it more information and ability to bypass the problem which has been existing with the method. Further, it enables it estimate the environmental wellness and diversity levels under non-comparative situations.

\section{Recommendation}

There is need to enhance the accuracy in estimation of the environmental wellness and biodiversity levels by integrating the logarithmic indices of the size of land occupied by species, as another parameter and many other variables that can estimate wellness. This will give a near true magnitude of environmental wellness. This is possible because the modified model is open ended. Thus, can accommodate as many variables as possible.

\section{Acknowledgement}

Firstly, the author (s) would like to thank the Masinde Muliro University of Science and Technology for provision of general research infrastructure. Secondly, the entire Biological sciences department for hosting the simulation experiments and the necessary technical support provided during the study. Above all, the almighty God for surrounding us with a world full of knowledge gaps to explore.

\section{Conflict of interest declaration}

The authors declare that there is no conflict of interest regarding the publication of this paper.

\section{References}

Gilbert Barrantes and Luis Sandoval (2009) "Conceptual and statistical problems associated with the use of diversity indices in ecology" Revista de biología tropical, Vol. 57, No. 3, September 2009, pp. 451-460

Causton R.D. and Venus C.S. (1981) "The biometry of plant growth" Edward Arnold Publishers Ltd, Bedford square, London.

Anne Chao and Tsung-Jen Shen (2003) "Nonparametric estimation of Shannon's index of diversity when there are unseen species in sample" Environmental and ecological statistics Vol.10, No. 4, December 2003, pp. 429-443

Fattorini, L. (2003) "Statistical analysis of ecological diversity" Environmetrics; El-Shaarawi, AH, Jureckova, J., Eds, pp. 18-29

Stefano A. Gattone and Tonio Di Battista (2009) "A functional approach to diversity profiles" Journal of the Royal Statistical Society: Series C (Applied Statistics) Vol. 58, No.2, September 2008, pp. 267-284

Hanski, I. (1998) "Metapopulation dynamics” Nature Vol. 396 No. 6706: 41

Heip C. H., Herman P. M., and Soetaert K. (1998) "Indices of diversity and evenness" Oceanis, 24 (4): 61-88 (1998).

Hunt, R. (1982) "Plant growth curves: The functional approach to plant growth analysis" Edward Arnold Publishers Ltd, Bedford square, London. 
Hunt R., Causton R.D., Shipley B. and Askew P.A. (2002) "A modern tool for classical plant growth analysis" Annals of Botany Vol. 90, pp. 485- 488 (2002).

Itô Y. (2007) "Recommendations for the use of species diversity indices with reference to a recently published article as an example" Ecological research Vol. 22 No. 4: 703-705

Jastrzębska M., Szarejko T., Hołdyński C., and Jastrzębski W. P. (2009) "Species diversity in grassland communities under different habitat conditions" Polish Journal of Natural Sciences, 24 (1): 43-59 (2009).

Karlson, R. H. and Cornell H. V. (1999) "Integration of local and regional perspectives on the species richness of coral assemblages" American Zoologist Vol. 39, No.1, pp. 104-112

Keylock C. J. (2005) "Simpson diversity and the Shannon-Wiener index as special cases of a generalized entropy" Oikos Vol.109 No.1: 203-207

Li J. (2019) "A critical review of spatial predictive modeling process in environmental sciences with reproducible examples in R” Applied Sciences Vol. 9 No. 2048: 1-23

Magurran A.E. (1988) "Ecological diversity and its measurement” Princeton University Press, Princeton.

Magurran A.E. (2004) "Measuring biological diversity” Blackwell Publishers Ltd, Oxford, UK.

Milbrink G. (1983) "An improved environmental index based on the relative abundance of oligochaete species" Hydrobiologia Vol.102 No. 2: 89-97

Okpiliya, F. I. (2012) "Ecological diversity indices" Any hope for one again Journal of Environment and Earth Science Vol. 2 No.10: 45-52

Omayio O. D. (2018) "Morphological and molecular characterization, pathogenicity and co-infection effects of Ustilago kamerunensis with 'Candidatus Phytoplasma oryzae' strain Mbita 1 on napier grass growth tolerance under varying nutrients and moisture levels” $\mathrm{PhD}$ thesis, Maseno University publication, MasenoKenya.

Omayio O. D., Musyimi M. D., Muyekho N. F., Ajanga I. S., Midega A.O. C., Khan R. Z., and Kariuki W. I. (2018) "Introducing a novel natural logarithmic indices and their corresponding percentages table towards quantitative estimation of plant tolerance levels to stressors" International Journal of Biosciences, 12 (4):7898 (2018). Http://dx.doi.org/10.12692/ijb/12.4.78-98.

Parry, D. (1990) "Plant pathology in agriculture" Cambridge University Press, Great Britain.

Ricotta C., and Szeidl, L. (2006) "Towards a unifying approach to diversity measures: bridging the gap between the Shannon entropy and Rao's quadratic index" Theoretical population biology Vol. 70, No. 3, pp. 237-243

Roth, D.S., Perfecto, I. and Rathcke, B. (1994). "The effects of management systems on ground foraging and diversity in Costa Rica" Ecologicl applications 4(3):423-436

Russell, K.G. (1991) "Estimating the value of e by simulation" The American Statistician 45: 66-68

Sarma, P., and Das, D. (2004) “Application of Shannon's Index to Study Diversity with Reference to Census Data of Assam" Asian Journal of Management Research Vol. 5, No. 4, pp. 620-628

Schmidt M., Thiombiano A., Dressler S., Hahn-Hadjali, K., Guinko S. and Zizka, G. (2010). "Phytodiversity data strengths and weaknesses, a comparison of collection and relevé data from Burkina Faso" Systematics and conservation of African plants, pp. 829-837 (2010).

Spellerberg, I. F. and Fedor, P. J. (2003). "A tribute to Claude Shannon (1916-2001) and a plea for more rigorous use of species richness, species diversity and the 'Shannon-Wiener'Index" Global ecology and biogeography Vol.12, No. 3, pp. 177-179

Umbarger, D. (2006). "Explaining logarithms: A progression of ideas illuminating an important mathematical concept" Brown books publishing group, Dallas, TX, USA.

Zar, H.J. (2010). "Biostatistical analysis". $5^{\text {th }}$ Edition, Prentice Hall Inc. Upper Saddle River, New Jersey. 